UDC [1:316] (430)

LBC 87.6

\title{
SOCIAL PHILOSOPHICAL DISCOURSE OF THE WORLD RISK SOCIETY IN A PANDEMIC SITUATION
}

\author{
Olga M. Lomako \\ Saratov State University named after N.G. Chernyshevski, Saratov, Russian Federation
}

\begin{abstract}
The author considers the situation associated with coronavirus pandemic and its possible consequences for social cultural processes. The difficulty in risk analysis is that the risk is between objective and subjective, between rational and irrational, between social and existential. The logic of uniqueness gives way to the logic of ambiguity, which finds its expression in the connection of the risk society with the cosmopolitism. Ulrich Beck's concept of the cosmopolitan turn of modern civilization is updated, which is revealed through the concepts of "danger", "social inequality" and through the existentials "fear", "uncertainty", which indicate the social vulnerability of modern society. We are talking about the need to distinguish between risk and danger, about their complex relationship in modern conditions. Global risks include the coronovirus pandemic: risk has become a global hazard from which future risks and crises originate. The reflexivity of the unknown and the methodological cosmopolitanism - point to a global change in the society in the $21^{\text {st }}$ century, whose priority is security. Cosmopolitanism is expressed in social delocalization, which includes three dimensions: spatial, temporal, and social. Risks have symbolic and existential content and include life guidelines, traditions and cultural norms. The coronavirus was a challenge to the intellectual sphere of society. The author focuses on the transformation of risks in the field of science and education. Self-isolation and social distance initiate the active introduction of distance education and media education. Attempts are being made to identify possible risks resulting from the introduction of media technologies in the educational system. The concept of the multiplicity of interpretations of riskogenics allows us to understand the prospects for the transformation of the global risk society in a pandemic situation.
\end{abstract}

Key words: social philosophy, world risk society, pandemic, security, methodological cosmopolitanism, social risk discourses, media education.

Citation. Lomako O.M. Social Philosophical Discourse of the World Risk Society in a Pandemic Situation. Logos et Praxis, 2021, vol. 20, no. 2, pp. 25-30. (in Russian). DOI: https://doi.org/10.15688/lp.jvolsu.2021.2.3

УДК [1: 316] (430)

ББК 87.6

\section{ФИЛОСОФСКИЕ ДИСКУРСЫ МИРОВОГО ОБЩЕСТВА РИСКА В СИТУАЦИИ ПАНДЕМИИ}

\author{
Ольга Михайловна Ломако \\ Саратовский государственный университет им. Н.Г. Чернышевского, г. Саратов, Российская Федерация
}

Аннотация. В статье рассматриваются ситуация, связанная с пандемией коронавируса в мировом обществе риска, и ее возможные последствия для социокультурных процессов. Трудность в социальнофилософском анализе риска заключается в том, что риск находится между субъективным и объективным, между рациональным и иррациональным, между социальным и экзистенциальным. Логика однозначности уступает место логике многозначности, которая находит свое выражение в соединении общества риска с космополитизмом. Актуализируется концепция У. Бека о космополитическом повороте современной цивилизации, это раскрывается через понятия «опасность», «социальное неравенство» и через экзистенциалы «страх», «неуверенность», которые свидетельствуют о социальной уязвимости современного общества. Речь идет о необходимости различения риска и опасности, о их сложной взаимосвязи в современных условиях. К глобальным рискам относится пандемия коронавируса: риск стал глобальной опасностью, из которой () берут начало будущие риски и кризисы. Рефлексивность неизвестного и методологический космополитизм 
указывают на изменение социального бытия в XXI в., приоритетом которого становится безопасность. Космополитизм выражается в социальной делокализации, которая включает три измерения: пространственное, темпоральное и социальное. Риски обладают символическим и экзистенциальным содержанием и включают жизненные ориентиры, традиции и нормы культуры. Коронавирус явился вызовом интеллектуальной сфере общества. Автор акцентирует внимание на трансформации рисков в области науки и образования. Самоизоляция и социальная дистанция инициируют активное внедрение дистанционного образования и медиаобразования. Предпринимаются попытки выявления возможных рисков в результате внедрения медиатехнологий в образовательную систему. Представление о множественности трактовок рискогенности позволяет осмыслить перспективы трансформации мирового общества риска в ситуации пандемии.

Ключевые слова: социальная философия, мировое общество риска, пандемия, безопасность, методологический космополитизм, социальные дискурсы риска, медиаобразование.

Цитирование. Ломако О. М. Философские дискурсы мирового общества риска в ситуации пандемии // Logos et Praxis. - 2021. - T. 20, № 2. - C. 25-30. - DOI: https://doi.org/10.15688/lp.jvolsu.2021.2.3

Взрыв пандемии коронавируса и борьба с ним означают вызов и двойную ответственность для науки. Пандемия изменила роль образования в обществе. Еще никогда прежде она не была настолько в центре внимания социума, поскольку никогда прежде не оказывалась компасом не только для политических решений, но и для всех сфер общественной жизни. Это значение научных исследований и внимание к ним раскрывают огромную ответственность. В то же время COVID-19 представляет многостороннее поле для изучения. Поэтому стало очевидным, насколько важной является кооперация в науке как в национальном, так и в интернациональном масштабе. В условиях эпидемии выявилась также ценность сохранения знаний. Вполне очевидно, что в период продолжительной пандемии общественность и политика ждут от исследователей быстрых и эффективных результатов [Becker 2020, 2-3].

Первым ответом на вызов SARS-CoV-2 стало обращение к футурологии и прогнозированию - бегство в будущее, словно по сравнению с будущим настоящие проблемы не так уж и важны. «Каким будет мир после пандемии?»- вот вопрос, который задают политики, экономисты, представители разных областей знания и практики. «Однако в условиях не просто пандемии, а общего кризиса понятие “мир после пандемии” оказывается слишком сильным обобщением - и для описания текущей реальности, и как концепт... Такие обобщения... исключают из поля зрения сверхсуммативность, когда на фоне собственной логики развития биокатаклизма взаимосвязанные изменения в политике, экономике, технологиях и институтах вступают в контакт с движениями в сфере идеологии и культуры, сознания и бессознательного, запуская процессы обвального характера» [Рубцов 2020, 23-24].

Приоритетными направлениями становятся ранняя диагностика, исследование причин и интенсивности воздействия на человеческий организм эпидемий и пандемий на примере SARS-CoV-2 и других патогенных микроорганизмов и вирусов. Сюда относятся также психологические, общественные и культурные факторы возникновения, распространения и лечения эпидемий, включая правовые и этические импликации.

В своем проекте под названием «Политическая иммунология» Б.В. Марков проводит аналитику биологического, социально-исторического и культурно-символического контекстов дискуссий о природе COVID-19. Он приходит к неутешительному выводу, что наше представление о том, какими должны быть отношения человека с природой, оказывается весьма сомнительным: «Экологический и, наконец, вирусологический кризис со всей отчетливостью показывает, что ее капиталистическое освоение представляет собой угрозу выживанию человечества» [Марков 2021, 4]. Продолжая свою мысль, он говорит, что первой необходимостью при осмыслении начала пандемии была попытка сопротивления врагу-вирусу. Усилия ученых нацелены на разработку нового оружия - лекарств, средств индивидуальной защиты и вакцины; медики, спасая больных, рискуют как на войне - собственной жизнью. Страх, неопределенность и изоляция достаются обывателю. Паника, охватившая людей, подталкивает к вопросу: «В чем причина страхов и не свиде- 
тельствуют ли они об уязвимости современного общества?» [Марков 2021, 5].

В своем фундаментальном труде «Мировое общество риска. В поиске утраченной безопасности» У. Бек рассматривает соотношение риска и социальной уязвимости, подчеркивая, что данные понятия представляют по сути две стороны одной медали. Эта простая мудрость разделяется всеми подходами к изучению риска как некоего совокупного продукта. Более того, без определения понятия социальной уязвимости речь о глобальных опасностях теряет всякое содержание. В последние годы термин «уязвимость» постепенно стал ключевым в исследованиях рисков и теперь составляет ядро глобального социально-структурного анализа. Социальная уязвимость есть суммарный термин, включающий средства и возможности, которыми располагают индивиды, общества и целые народы для того, чтобы осмыслить риски и последствия в самом их бытии. Социально-философское понятие уязвимости имеет решающее отношение к будущему, оставаясь при этом тесно связанным со всей глубиной прошлого, поскольку «культурные раны» образуют значимый фон для понимания космополитических конфликтов. Чем более маргинальными являются экономические и политические возможности определенной социальной группы, тем уязвимее она. Но что означает уязвимость в определенном контексте и как она приобрела свою значимость?

Согласно концепции У. Бека, социальная уязвимость не ограничивается ни временем, ни пространством, а может пониматься методологически только из космополитического момента. «Последовательное проведение космополитического анализа позволяет вскрыть космополитические патологии, в которых перекрещивание природных и социальных условий и опасностей могут разжечь величайшие катаклизмы XXI века» [Beck $2015,322]$. Именно таким катаклизмом явилась пандемия коронавируса с ее глобальным кризисом.

Герд Гигеренцер, директор «Центра компетенции по риску» (Zentrum für Risikokompetenz), основанного в Германии в 2009 г., в монографии «Риск. Как принимают правильные решения〉 обращает внимание на важность пони- мания природы рисков и их последствий прежде всего в области медицины. С большим сожалением он отмечает полное отсутствие в учебных планах большинства медицинских факультетов проблематики рисков. Иначе говоря, «врачи учатся всему, но только не тому, как оценивать риски» [Gigerenzer 2014, 209].

Риск означает предвидение неизвестного, предсказание непредсказуемого. В начале XXI в. каждое действие связано с ним. Он становится глобальным. На вопрос о том, что же определяет глобальные риски, немецкий социолог и философ У. Бек дает четкий ответ: это прежде всего делокализация, (Delokalisation), которая означает, что причины и следствия совершаемых действий больше не ограничены каким-либо одним географическим местом или пространством. Они в принципе пронизывают собой все и присутствуют везде. При этом последствия рисков не могут быть предусмотрены и просчитаны. Это значит, что риски являются лишь гипотетическими, поскольку речь идет о предсказании непредсказуемого. «Делокализация связана, в свою очередь, с невозможностью компенсирования современных рисков, поскольку их последствия необратимы» [Beck 2015, 103]. Так, например, бесповоротным является изменение климата, прогресс в генетике. Несомненно, возникновение молекулярной медицины явилось сменой парадигмы в науке. Если диагностика происходит не с помощью клинического исследования и аппаратурного измерения, а определяет изменения генома и протеома - это означает очевидный научный прогресс. Предикативная генная диагностика, обладая генетической информацией, рассматривает вопросы будущего далеко за границами терапии, а возможность многих заболеваний или частота некоторых предрасположенностей могут быть определены, от этого во многом зависят индивидуальные жизненные планы и социальные проекты. Знание о повышенных рисках заболеваний может способствовать их предотвращению. Однако, с другой стороны, «генная инженерия открывает дверь к проникновению рисков, имеющих далеко идущие негативные последствия» [Bruchhausen, Schott 2008, 216]. Если прогресс в генетике вторгается в человеческую природу необратимым для нее способом, уже не приходится говорить о какой-либо 
компенсации риска, поскольку разрушается сама логика этого.

Методологический космополитизм должен пониматься в этом смысле как «формирующаяся исследовательская повестка дня» (Forschungsagenda), которая позволяет возвратится к исходному предмету анализа современной реальности - действительности, ставшей ни национальной, ни интернациональной, а космополитической. Такой ракурс исследования открывает горизонт для «космополитического реализма» - новой критической теории мирового общества риска, основной смысл которой заключается в том, что внешние опасности воспринимаются как опасности внутренние.

При этом глобализация внешних проблем как проблем внутренних следует своей собственной логике. «Внешние опасности являются латентными последствиями биологических, технических, экономических решений, принимаемых как государствами, так и отдельными индивидами. Чем новее проблемы, тем более они непостижимы, тем труднее становится предвидение реальной опасности» [Beck 2015, 288]. Именно к таким опасностям относится пандемия коронавируса: риск стал глобальной угрозой, из которой берут начало будущие риски и кризисы.

Речь идет об антагонизме риска, который кроется в самой его логике - противостояние между теми, кто принимает решения (Entschlosser), и пострадавшими (Betroffene) социальными группами, народами, которые страдают от этих решений и их последствий. Такое социальное неравенство есть продукт особого рода, рождаемый внутренней логикой риска, суть которой в предвидении непредсказуемого.

Тот, кто пытается раскрыть связь риска и социального неравенства, должен определить суть социально-философского понятия риска. Он не задается изначально, лишь впоследствии распределяется социально неравномерно, так что риск и социальное неравенство оказываются неразрывно связанными. Эта асимметрия и заключающееся в ней противостояние дальнейших жизненных перспектив не являются чем-то поверхностным и побочным, а составляют саму сущность риска.
Очень часто риск и опасность понимают как одно и то же. Если опасность приходит извне, то риск всегда предполагает собой чье-либо решение. Следовательно, тот, кто это решение принимает, производит тем самым радикальную асимметрию между теми, кто принимая решение, отваживается на риск и предвидит его последствия, и теми, кому предопределено и предписано нести на себе, на своем здоровье и жизни последствия чужих решений, не имея никакой возможности както повлиять на ситуацию, будучи не в состоянии принять какое-то участие в исполнении решений [Beck 2015, 252].

По убеждению Н. Лумана, риски представляют собой специфическую форму диспозиции будущего, «двусторонний медиум вероятного / невероятного, переход от одной стороны к другой» [Luhmann 2003, 81]. Можно принять рискованное решение или ждать, но при этом ожидание также оборачивается риском. Речь идет о различии риска как предвиденной катастрофы и катастрофы фактической. В данном случае глобальный риск понимается как инсценировка возможной реальности мирового риска. Именно через инсценировку мирового риска будущая катастрофа представляется как существующая в настоящем. При этом сам термин «инсценировка» вовсе не означает - как это часто встречается в обыденном мышлении и в разговорной речи - некую фальсификацию действительности через преувеличение «нереальных» рисков. Феномен «инсценировки риска» детерминирован мировым обществом риска.

Все стороны социального бытия пронизаны рисками, обретающими глобальный характер: экономика, политика, медицина и т. д. Большую тревогу вызывают риски, связанные с состоянием современного образования, с необходимостью перехода на дистанционные формы обучения. Информация и дигитализация становятся новой «религией» - тем проектом, согласно которому «нет субстанционального различия между субъектом и объектом, между человеком и техникой» [Feustel $2018,137]$. Принципиальное изменение статуса информации в информационном обществе означает тотальное расширение ее негативных возможностей практически во всех сферах социальной действительности, в том чис- 
ле, несомненно, в сфере образования, которое в условиях пандемии стало дистанционным.

Как справедливо замечает В.В. Савчук, при дистанционной форме образования «главными требованиями полагаются способ трансляции информационного материала, его наглядность и доступность. Однако возможность доступности информации приходит в противоречие с ее реальным избытком. В результате важным оказывается не столько поиск информации и не сама информация, сколько отсеивание ненужной и ложной информации. Как следствие, рождается новая форма бегства от свободы и новая форма отчуждения через подчинение сетевому коллективному разуму» [Савчук 2020, 84-85].

В начале июня 2020 г. в Германии была образована междисциплинарная комиссия исследования пандемии, в которую вошли 18 представителей из разных областей науки, включая исследования в сфере образования. Приоритетом является анализ кризисной устойчивости (Krisenresistenz) образовательной сферы и направлений инноваций в области дигитализации обучения - это и есть та необходимость, которую диктует опыт пандемии. Какие ресурсы, компетенции и условия нужны системе образования - вопрос не новый, но с учетом условий пандемии он встает с большей настойчивостью и требует ответа [Unterstell 2020, 4-5].

Вопросы медиаобразования, дигитализации образования в условиях пандемии стали предметом дискуссий в России и далеко за ее пределами, обретая космополитический характер. Предпринимаются попытки выявления возможных рисков в результате внедрения медиатехнологий в образовательную систему. Разводя понятия «медиаобразование» и «образование», А.И. Стребков предостерегает как от «абсолютизации медиаобразования», так и от его «принудительного насаждения» в педагогический процесс, что может привести к риску «возвращения догматизма в образовании». При этом автор подчеркивает, что внедрение дигитализации в образование «должно стать естественным процессом и потребностью той или иной образовательной программы; лишь компетентностная необходимость должна выступать основополагающим критерием инкорпорации медиаобра- зовательных технологий» [Стребков 2020, 5]. Образование как творческий процесс формирования образа человека требует особой атмосферы, определенного места погруженности в интеллектуальную работу, совместного проживания дискурсивного события.

Риски не являются ценностно нейтральными, они обладают символическим и экзистенциальным содержанием, которое включает жизненные ориентиры, традиции и нормы культуры. Так, география и топография города благодаря изменению жилища, соответственно, условиям комфорта - определили условия реализации индивидуализма в эпоху Модерна. Однако решение этой проблемы тут же породило другую - одиночество человека и его неукорененность. Если прежнее место понималось как ойкумена, где воспитывалось чувство солидарности и взаимопонимания, то современное городское жилище больше всего похоже на обитаемый остров для изолированного индивида [Ломако 2014, 50]. Город диктует совершенно определенный - «городской» - стиль отдыха. Возникают анимационные центры, гипермаркеты и другие места комфортабельного досуга и массового развлечения. Пребывание в местах скопления людей, растворение в массе часто означают для человека и отдых от него самого. Требование социальной дистанции и длительной самоизоляции как необходимые условия борьбы с пандемией явились серьезным психологическим испытанием прежде всего для жителей больших городов.

Пожалуй, основная трудность в анализе риска заключается в том, что риск находится между рациональным и иррациональным, между определенностью и неопределенностью, субъективностью и объективностью. Логика однозначности уступает место логике многозначности, которая находит свое выражение в соединении общества риска с космополитизмом. Возникновение пандемии привело к изменению многих философских понятий и метафор описания современного общества. Так, самоизоляция и социальная дистанция, надежность и ненадежность, доверие и ожидание, надежда и разочарование, страх и неуверенность наполняются новым содержанием и активно включаются в семантику социальнофилософского дискурса. Трансформация мирового общества риска в ситуации наступле- 
ния COVID-19 инициирует появление новых философских дискурсов, направленных на создание общей планетарной ответственности, на поиск новых возможностей минимизации рисков и опасностей настоящего с ориентиром на будущее.

\section{СПИСОК ЛИТЕРАТУРЫ}

Ломако 2014 - Ломако О.М. Трансформация власти в большом городе: генеалогия и аналитика // Власть. 2014. № 3. С. 48-51.

Марков 2021 - Марков Б.В. Политическая иммунология. М.: Проспект, 2021.

Рубцов 2020 - Рубияов A.B. Вирусы и цивилизация. О новом влиянии биокатаклизмов на эволюцию социокультурных моделей и цивилизационных проектов // Вопросы философии. 2020. № 8. C. 20-31.

Савчук 2020 - Савчук В.В. Медиаобразование эпифеномен цифровизации // Вопросы философии. 2020. № 5. С. 83-86.

Стребков 2020 - Стребков А.И. Медиаобразование и образование: риски, потери и приобретения // Вопросы философии. 2020. № 3. С. 5-8.

Beck 2015 - Beck U. Weltrisikogesellschaft. Auf der Suche nach der verlorenen Sicherheit. Frankfurt am Main: Suhrkamp Verlag, 2015.

Becker 2020 - Becker $K$. Mit exzellenten Grundlagen und Gemeinschaftssinn // Forschung. 2020. No. 2. S. 2-3.

Bruchhausen, Schott 2008 - Bruchhausen W., Schott $H$. Geschichte, Theorie und Ethik der Medizin. Göttingen: Vandenhoek \& Ruprecht, 2008.

Feustel 2018 - Feustel $R$. Am Anfang war die Information. Berlin, Verbrecher Verlag, 2018.

Gigerenzer 2014 - Gigerenzer G. Risiko. München: Verlag Random House GmbH, 2014.
Luhmann 2003 - Luhmann N. Soziologie des Risikos. Berlin; N. Y.: Walter de Gruyter, 2003.

Unterstell 2020 - Unterstell R. Richtungsweisende Perspektiven // Forschung. 2020. № 3. S. 4-5.

\section{REFERENCES}

Lomako O.M., 2014. The Transformation of Power in a City: Genealogy and Analytics. Vlast', no. 3, pp. 48-51.

Markov B.V., 2021. Political Immunology. Moscow, Prospekt Publ.

Rubcov A.V., 2020. Viruses and Civilization. About the New Bio-Disasters Influence on the Evolution of Socio-Cultural Models and Civilizational Projects. Voprosy filosofii, no. 8, pp. 20-31.

Savchuk V.V., 2020. Media Education is an Epiphenomenon of Digitalization. Voprosy filosofii, no. 5, pp. 83-86.

Strebkov A.I., 2020. Media Education and Education: Risks, Losses and Acquisitions. Voprosy filosofii, no. 3, pp. 5-8.

Beck U., 2015. World Risk Society. In Search of the Lost Security. Frankfurt am Main, Suhrkamp Verlag Publ.

Becker K., 2020. With Excellent Foundations and a Sense of Community. Forschung, no. 2, pp. 2-3.

Bruchhausen W., Schott H., 2008. History, Theory and Ethics of Medicine. Göttingen, Vandenhoek \& Ruprecht Publ.

Feustel R., 2018. At the Beginning Was the Information. Berlin, Verbrecher Publ.

Gigerenzer G., 2014. Risiko. Munich, Random House GmbH Publ.

Luhmann N., 2003. Sociology of Risk. Berlin, New York, Walter de Gruyter Publ.

Unterstell R., 2020. Groundbreaking Perspectives. Forschung, no. 3, pp. 4-5.

\section{Information About the Author}

Olga M. Lomako, Doctor of Sciences (Philosophy), Professor, Department of Theoretical and Social Philosophy, Saratov State University named after N.G. Chernyshevski, Astrakhanskaya St, 83, 410012 Saratov, Russian Federation, olga-lomako@yandex.ru, https://orcid.org/0000-0003-0543-0379

\section{Информация об авторе}

Ольга Михайловна Ломако, доктор философских наук, профессор кафедры теоретической и социальной философии, Саратовский государственный университет им. Н.Г. Чернышевского, ул. Астраханская, 83, 410012 г. Саратов, Российская Федерация, olga-lomako@yandex.ru, https://orcid.org/0000-0003-0543-0379 